\title{
Induction of puberty and synchronization of estrus in gilts with eCG and GnRH
}

\section{Camilla Pereira de Souza Labêta ${ }^{*}$ (iD), Bruno da Silva de Vasconcelos ${ }^{2}$, Marco Roberto Bourg de Mello ${ }^{3}$}

\author{
${ }^{1}$ Universidade Federal Rural do Rio de Janeiro, Programa de Pós-graduação em Zootecnia, Seropédica, RJ, Brasil. \\ ${ }^{2}$ Universidade Federal Rural do Rio de Janeiro, Setor de Suinocultura, Seropédica, RJ, Brasil. \\ ${ }^{3}$ Universidade Federal Rural do Rio de Janeiro, Departamento de Reprodução e Avaliação Animal, Seropédica, RJ, Brasil.
}

\begin{abstract}
In this study, we investigated the effects of eCG and GnRH on the induction of puberty in prepubertal gilts and evaluated the pregnancy rate and litter size in these females. Thirty 140-day-old gilts with an average weight of $80 \mathrm{~kg}$ were randomly divided into two treatments: hormonal treatment $(n=15)$ : $1000 \mathrm{IU}$ of eCG and $50 \mu \mathrm{g}$ of GnRH; and control group $(n=15)$ : induction of estrus by male presence. Gilts were inseminated at the second estrus and pregnancy was confirmed by the non-return to estrus. At farrowing, litter size, average piglet weight, and number of stillborn and mummified piglets were recorded for analysis. The variable pregnancy rate was subjected to the Chi-square test $\left(\chi^{2}\right)$, while variables age at first estrus, weight at insemination, and duration of first and second estrus, litter size, average weight, and average number of dead and mummified piglets were analyzed by the $t$ test. Hormonal treatment induced puberty in $100 \%$ of the gilts in four days. There was a difference in age at first estrus and in weight at insemination. Animals in the control group had the first estrus later and weighed more than those under hormonal treatment (167 vs. 143 days, 117 vs. $102 \mathrm{~kg}$, respectively). However, there was no difference between the two groups in the duration of first and second estrus ( 54 vs. 49 h, 45 vs. 36 h, respectively), in pregnancy rate ( 100 vs. $86 \%$, respectively), litter size, average piglet weight, and number of dead and mummified piglets between the hormonal treatment and control animals ( 9.0 vs. 9.8 piglets, 1.3 vs. $1.3 \mathrm{~kg}$, and 3.0 vs. 2.3 dead and mummified, respectively). The hormonal treatment is effective in inducing precocious puberty without impairing pregnancy rate and litter size as well as average weight of piglets.
\end{abstract}

Key Words: animal production, reproduction, swine

\section{Introduction}

The management of gilt puberty induction using the male is through daily contact with the boar; however, this management leads to a wide range of ages at puberty within a group of gilts. These variable ages can cause management and logistic problems to the breeder due to non-synchronized estrus cycles, which may be late or early, thus compromising the insemination programs. Besides, there are females that do not show any signs of estrus with exposure to the male.

According to Knox et al. (2000), hormonal protocols represent an effective way to induce estrus in gilts, in which only the stimulation of male exposure has not been effective, as well as synchronization of a group of gilts and for early puberty. The use of hormones is a tool used

Received: January 3, 2018

Accepted: April 30, 2018

*Corresponding author: labetacps@outlook.com

Copyright (C) 2018 Sociedade Brasileira de Zootecnia. This is an Open Access article distributed under the terms of the Creative Commons Attribution License (http://creativecommons.org/licenses/by/4.0/), which permits unrestricted use, distribution, and reproduction in any medium, provided the original work is properly cited. to induce puberty in gilts and to homogenize groups so that inseminations, births, and weaning are concentrated in a certain period, facilitating routine farm management through estrus synchronization. This study aimed to evaluate the use of a hormonal protocol on the induction of puberty in prepubertal gilts and to evaluate pregnancy rate and litter size of prepubertal gilts after estrus induction with GnRH associated with eCG.

\section{Material and Methods}

Research on animals was conducted according to the institutional committee on animal use (case no. 7885010616). This study was performed in a school farm located at Seropedica, Rio de Janeiro State in Brazil (latitude: 2246'40.908" S, longitude: 43³9'59.296" W, elevation: $26 \mathrm{~m}$ ) from September 2016 to April 2017.

Thirty 140-day-old gilts weighing $80 \mathrm{~kg}$ were used. These females had heterogeneous characteristics and were obtained from breeding four breeds on the farm (Landrace, Large White, Duroc, and Pietrain). Gilts were maintained in collective or individual pens according to the experimental phase. Water was supplied ad libitum throughout the 
experiment, and feeding was according to the farm routine. Animals were divided into two treatments: hormonal treatment - intramuscular application of 1000 IU equine chorionic gonadotrophin (eCG) (Folligon ${ }^{\circledR}$, MSD Animal Health - São Paulo/Brazil) and then $50 \mu \mathrm{g}$ lecirelin, (GnRH analogue) (Gestran plus ${ }^{\circledR}$, Tecnopec - São Paulo/Brazil) $80 \mathrm{~h}$ after eCG administration; and the control group induction of estrus through male stimulation.

For puberty induction, gilts remained in collective pens, housed in groups of five animals receiving growth feed. All gilts, regardless of the treatment, had contact with the boar twice a day (morning and afternoon) for $10 \mathrm{~min}$ until positive appearance of standing reflex to record age at first estrus. However, exposure of male to the group of hormonal treatment was after administration of eCG, and animals in control group were exposed to the male when they were 140 days old. Heat detection was carried out on both groups until the appearance of negative standing reflex, thereby obtaining the duration of first estrus.

Females were inseminated in the subsequent estrus, 18 to 24 days after first estrus, two to three times, depending on the duration of estrus of each gilt, and inseminations were done at 0,12 , and $24 \mathrm{~h}$ after identification of a positive estrus with cooled diluted semen. Then, gilts were placed in individual pens and received gestation feed, according to farm routine. After artificial insemination, gilts were weighed to obtain their weight at insemination. Estrus check was also performed until the appearance of a negative appearance of standing reflex to obtain duration of second estrus.

The return, or not, of the third estrus of gilts, using the male, was used as a pregnancy diagnosis. Females that did not return to estrus were considered pregnant and were kept in collective pens according to farm routine and received gestation feed.

Pregnant females were sent to individual maternity pens when they completed 104 days of gestation and, at 113 days, all females had induced farrowing with a $132.5 \mu \mathrm{g}$ application of cloprostenol (Ciosin ${ }^{\circledR}$, MSD Animal Health - São Paulo, Brazil). After farrowing, litter size, mean weight of piglets, and number of dead and mummified piglets were recorded.

The experiment was conducted under a completely randomized design in the form of time-repeated measurements. The variable pregnancy rate was subjected to the chi-square test $\left(\chi^{2}\right)$, while variables age at first estrus, weight at insemination, and duration of first and second estrus, litter size, average piglet weight, and number of dead and mummified piglets were analyzed by the $t$ test $(\alpha=0.05)$, using the statistical program GraphPad Prism ${ }^{\circledR}$, version 5.0 for Windows ${ }^{\circledR}$.

\section{Results}

In the hormonal treatment group, the first estrus occurred at a younger age $(\mathrm{P}<0.05)$, which demonstrated that this treatment was effective in inducing precocious puberty, with a mean of 143.6 days old compared with induction of puberty only with stimulation of the male (control), which occurred on average when gilts were 167.7 days old. Hormonal treatment induced the first estrus in $100 \%$ of gilts three to four days after application of eCG, while in control group, the first estrus occurred in all gilts ranging from three to 58 days after the beginning of the stimulation with the boar (Table 1).

Gilts which expressed the second estrus within a seven-day-interval were considered as synchronized. Animals induced with hormonal treatment expressed the second estrus within a two-day-interval and, thus, were considered as synchronized, while control animals were considered non-synchronized due to the second estrus occurring in a heterogeneous way within a mean period of 19 days (Table 1).

Among the gilts that received hormonal treatment, $53 \%(\mathrm{~N}=8)$ had the second estrus apparent and were inseminated, while the others were discarded from the experiment because they did not present apparent estrus in the period from 18 to 24 days (estrus interval) after the first estrus. However, among the discarded gilts, four presented positive standing reflex in the period from 28 to 36 days after the first one. On the other hand, in the control group, $100 \%(\mathrm{~N}=15)$ of the gilts presented an apparent second estrus within the estrus range, and were, therefore, inseminated in this period (Table 1).

There was an increase in weight at insemination $(\mathrm{P}<0.05)$ in control animals (117 vs. $102 \mathrm{~kg}$, respectively). However, there was no difference $(\mathrm{P}>0.05)$ in pregnancy rate (100 vs. $86 \%$, respectively), and in litter size $(\mathrm{P}>0.05)$ with 9.0 piglets in hormonal treatment group and 9.8 piglets in the control group. Piglet weight was not influenced by treatments $(\mathrm{P}>0.05)$, with average of $1.3 \mathrm{~kg}$

Table 1 - Data observed in groups of gilts subjected to hormonal treatment (HT) and control

\begin{tabular}{lcc}
\hline Data & HT & Control \\
\hline Animals (n) & 15 & 15 \\
Animals that showed first estrus (n) & 15 & 15 \\
Minimum of days of induction until estrus (days) & 3 & 3 \\
Maximum days of induction until estrus (days) & 4 & 58 \\
Animals that showed second estrus (n) & 8 & 15 \\
Animals showing estrus out of the estrus interval (n) & 4 & 0 \\
Synchronization of second estrus expression (days) & 2 & 19 \\
Abortions (n) & 1 & 2 \\
\hline
\end{tabular}


in both treatments. Number of dead and mummified piglets did not differ statistically between hormonal treatment and control group, 3.0 vs 2.3 , respectively (Table 2 ). There was no difference in the duration of estrus between hormonal treatment and control $(\mathrm{P}>0.05)$. The first estrus was 54.86 and $49.60 \mathrm{~h}$, and the second was 45.00 and $36.80 \mathrm{~h}$ for the hormonal-treated and control animals, respectively (Table 3).

\section{Discussion}

There is a great variation of age at puberty and is regulated by internal factors, like breed, live weight, and depth of backfat, and management like nutrition, male exposure, and environmental factors, which are mediated by the reproductive endocrine axis (Evans and O'Doherty, 2001). The understanding of mechanisms that influence these factors is of great importance to reduce the number of non-productive days on the farm, as well as the formation of groups of females for insemination aiming to set up uniform groups and facilitate farm management. Early puberty provides the opportunity for two or three estrous cycles before the first artificial insemination, contributing to the preparation of the uterus, to ensure appropriate levels of progesterone in females. The litter size is correlated with the number of estrus before the first artificial insemination in primiparous females, but the initial effect of number of estrus is not significant in multiparous females (Young et al., 1990; Cottney et al., 2012).

The influence of the boar is limited due to the individual differences in responses, resulting in a greater or minor degree of estrus synchronization within the group, including females that do not show any signs of estrus. Compared with male exposure, exogenous hormonal treatments may induce a faster and more synchronous ovulatory response within gilts (Muniz et al., 2013).

The effect of hormonal protocols to induce puberty in gilts has been reported in other studies; however, there is variation in number of days from induction until the appearance of first estrus using either the hormonal protocol or only the stimulation of the male. Martinat-Botté et al. (2011) observed that the expression of the first estrus after administration of PG600 (combination of $400 \mathrm{IU}$ eCG and $200 \mathrm{IU}$ of hCG) occurred within three days in $96 \%$ of the non-pubescent gilts compared with $64 \%$ of control gilts expressing the first estrus in four days after stimulation with the male twice a day. However, the age at which that experiment was started was greater than in the present study, about 182 days old, and this factor may have higher percentage of gilts expressing estrus within seven days after the initiation of the stimulus with the passage of the boar. Stančić et al. (2012), using gilts with an average age of 160 days old, observed the first estrus in $85 \%$ of gilts, on average, four days after eCG administration. However, Vianna et al. (2006), studying the effects of administrating $600 \mathrm{IU}$ of eCG and $72 \mathrm{~h}$ later, $5 \mathrm{mg}$ of luteinizing hormone (LH) in 145-day-old pre-pubertal gilts, found that $40.9 \%$ had estrus within four days after the LH application. The reduced number of females that had their estrus induced within four days is related to the fact that the authors used two different hormones and different dosages than what was used in this work, which were eCG + LH instead of eCG +

Table 2 - Mean \pm SEM and P-value for the parameters evaluated in the groups of gilts subjected to hormonal treatment (HT) and those of control

\begin{tabular}{|c|c|c|c|c|}
\hline Parameter & HT & Control & P-value & CI $95 \%$ \\
\hline Age at puberty (days) $)^{1}$ & $143.6 \pm 0.14 \mathrm{a}$ & $167.7 \pm 4.44 b$ & 0.001 & -32.5315 .67 \\
\hline Weight at insemination $(\mathrm{kg})^{1}$ & $102.0 \pm 2.46 \mathrm{a}$ & $117.7 \pm 3.55 b$ & 0.006 & -12.7618 .64 \\
\hline Pregnancy rate $(\%)^{2}$ & $100 \mathrm{a}$ & $86 a$ & 0.526 & -1.742 .02 \\
\hline Litter size $^{1}$ & $9.0 \pm 0.91 \mathrm{a}$ & $9.8 \pm 0.94 \mathrm{a}$ & 0.552 & -0.772 .37 \\
\hline Piglet weight $(\mathrm{kg})^{1}$ & $1.3 \pm 0.05 \mathrm{a}$ & $1.3 \pm 0.05 \mathrm{a}$ & 0.696 & -0.520 .52 \\
\hline Dead and mummified piglets ${ }^{1}$ & $3.0 \pm 1.41 \mathrm{a}$ & $2.3 \pm 0.88 \mathrm{a}$ & 0.730 & $-3.03 \quad 5.69$ \\
\hline
\end{tabular}

SEM - standard error of the mean; CI - confidence interval.

${ }^{1}$ Means in the same row followed by different letters are different by the $t$ test $(\mathrm{P}<0.05)$.

${ }^{2}$ Means in the same row followed by different letters are different by the Chi-square test $(\mathrm{P}<0.05)$.

Table 3 - Mean \pm SEM and P-value for the duration of estrus evaluated in the groups of gilts subjected to hormonal treatment (HT) and those of control

\begin{tabular}{|c|c|c|c|c|}
\hline Duration of estrus (h) & HT & Control & P-value & CI 95\% \\
\hline First estrus & $54.9 \pm 3.01 \mathrm{a}$ & $49.6 \pm 2.84 \mathrm{a}$ & 0.214 & $-0.42 \quad 11.02$ \\
\hline Second estrus & $45.0 \pm 3.00 \mathrm{a}$ & $36.8 \pm 3.20 \mathrm{a}$ & 0.111 & -2.1214 .28 \\
\hline
\end{tabular}

SEM - standard error of the mean.

Means in the same row followed by different letters are different by the test $(\mathrm{P}<0.05)$. 
GnRH. Manjarin et al. (2009) used 153-day-old gilts, and $73.3 \%$ of the gilts treated with PG600 expressed estrus up to seven days after hormonal administration, whereas no gilts expressed estrus during the same period in the control.

The absence of second estrus apparent in most of the gilts subjected to hormonal treatment may be related to possible ovulation without the expression of estrus characteristics and, according to Tilton et al. (1995), may be related to the percentage of females that demonstrate estrus, since ovulation can occur even without estrus manifestation. Vianna et al. (2006) observed that only $39.39 \%$ of females expressed the second estrus after the induction of puberty with LH at 145 days old, following the hormonal protocol. However, when they slaughtered the gilts that did not present second estrus, the researchers observed that $57 \%$ of the gilts had corpus luteum and/or corpus albicans, which were considered to have hidden estrus, and $43 \%$ had no structure in the ovary, and therefore were considered immature. In addition, another possible cause for the non-expression of second synchronized estrus would be the formation of ovarian cysts that may lead the animals to anestrus. Martinat-Botté et al. (2011) observed $89 \%$ of gilts presenting the second estrus when PG600 was used, while only $74 \%$ in the control group expressed the second estrus. However, the percentage of females not expressing second estrus was due to the age of gilts, since sows that were 180 days old had not yet presented the first estrus even with daily exposure to the male since when they were 160 days old.

In this study, it was not possible to identify the reason for non-expression of second estrus, although some gilts expressed estrus 21 days after the expected date of expression of second estrus. This suggests that these females presented the second hidden estrus.

The duration of first and second estrus presented no difference, showing that there is a similarity in the reproductive endocrinology of gilts after the hormonal treatment with those of the control that presented natural estrus. Jong et al. (2013) observed no difference in the duration of the first estrus of gilts after induction of puberty with $1000 \mathrm{IU}$ of eCG compared with the control, as there was no difference in the duration of estrus when using a GnRH analogue (Maprelin) in gilts, compared with the control and use of eCG. Similarly, Driancourt et al. (2013) observed no change in estrus duration compared with the control, with a mean of $57 \mathrm{~h}$, nor between the different dosages $(6,10$, and $16 \mu \mathrm{g})$ of buserelin $(\mathrm{GnRH})$ in sows after weaning.

Holtz et al. (1999) did not observe a significant difference in weight at insemination between gilts treated with PG600 at 180 days old with $95.7 \mathrm{~kg}$ and the control animals at the first estrus with $109.2 \mathrm{~kg}$. Hidalgo et al. (2014) observed a difference in weight at insemination between gilts treated with PG600 and those that had estrus induced only with stimulation of the male; the gilts that received hormonal treatment and expressed estrus in up to seven days presented greater weight, $132.7 \mathrm{~kg}$, than control gilts that had estrus within 30 days after induction, $125.9 \mathrm{~kg}$. However, there was no difference between treatments with hormonal treatment and control with gilts after 30 days of induction $(129.7 \mathrm{~kg})$.

Pregnancy rate according to the observations of Patterson et al. (2016) were $98 \%$ in the first delivery of gilts treated with PG600 to induce first estrus and 98.6\% in animals that were not subjected to hormonal protocol. Eckhardt et al. (2014) compared two treatments for induction of puberty in gilts, one with $600 \mathrm{IU}$ of eCG and 2.5 of LH and another only with the stimulation with the male, and did not observe any difference in pregnancy rate between treatments with an average of 92.5 vs. $92.3 \%$, respectively.

The use of hormonal protocols did not influence parameters related to piglets. Hidalgo et al. (2014) observed no difference in total number of piglets born between the estrus group induced by PG600 and the control, with 12.3 and 11.8 piglets, respectively. A similar result was found by Holtz et al. (1999), who used the same hormonal treatment in gilts and did not observe any difference in litter size; in addition, 8.4 piglets were observed after the use of PG600 and 8.3 in the control. There was also no difference in average piglet weight between treatments, in which both had an average of $1.3 \mathrm{~kg}$ per piglet at birth. Vangroenweghe et al. (2016), using a GnRH analogue, observed 13.95 piglets for the treatment group and 13.76 piglets in the control, and the average weight of dead and mummified piglets was around $1.2 \mathrm{~kg}$ each in both treatments. Jong et al. (2013) did not observe a difference in the number of piglets born from animals treated with eCG or GnRH analog compared with the control (1.0 and 0.7 vs. 0.9 , respectively) and in the number of mummified piglets with mean of 0.2 , among the treatments.

The difference in the number of days for induction of puberty between females in the same treatment influenced the appearance of the second estrus, according to the estrus interval of 18 to 24 days, so that the later the puberty, the later the appearance of the second estrus apparent and the later the insemination. This difference in age between the animals of both treatments influenced weight at insemination; however, the difference in weight did not influence the other parameters such as pregnancy rate and those related to litter. 


\section{Conclusions}

The use of eCG associated with GnRH is effective to induce early puberty in gilts from 140 days old, promoting puberty to occur early, as well as enabling the synchronization of estrus, with no loss in the rate of pregnancy, the size of the litter, and the average weight of the piglets.

\section{References}

Cottney, P. D.; Magowan, E.; Ball, M. E. E. and Gordon, A. 2012. Effect of oestrus number of nulliparous sows at first service on first litter and lifetime performance. Livestock Science 146:5-12. https://doi.org/10.1016/j.livsci.2012.02.013

Driancourt, M. A.; Cox, P.; Rubion, S.; Harnois-milon, G.; Kemp, B. and Soede, N. M. 2013. Induction of an LH surge and ovulation by buserelin (as Receptal) allows breeding of weaned sows with a single fixed-time insemination. Theriogenology 80:391-399. https://doi.org/10.1016/j.theriogenology.2013.05.002

Eckhardt, O. H. O.; Martins, S. M. M. K.; Pinese, M. E.; Horta, F. C.; Rosseto, A. C.; Torres, M. A.; De Andrade, A. F. C.; Muro, B. B. D.; Marino, C. T.; Rodrigues, P. H. M. and Moretti, A. S. 2014. Gonadotropin-induced puberty does not impair reproductive performance of gilts over three parities. Reproduction in Domestic Animals 49:964-969. https://doi.org/10.1111/rda.12415

Evans, A. C. O. and O'Doherty, J. V. 2001. Endocrine changes and management factors affecting puberty in gilts. Livestock Production Science 68:1-12. https://doi.org/10.1016/S03016226(00)00202-5

Hidalgo, D. M.; Friendship, R. M.; Greiner, L.; Manjarín, R.; Amezcua, M. R.; Domínguez, J. C. and Kirkwood, R. N. 2014. Influence of gonadotrophin-induced first oestrus on gilt fertility. Reproduction in Domestic Animals 49:899-902. https://doi.org/ 10.1111/rda. 12390

Holtz, W.; Schmidt-Baulain, R.; Welp, C. and Wallenhorst, C. H. R. K. 1999. Effect of insemination of estrus-induced prepuberal gilts on ensuing reproductive performance and body weight. Animal Reproduction Science 57:177-183. https://doi.org/10.1016/ S0378-4320(99)00054-8

Jong, E.; Kauffold, J.; Engl, S.; Jourquin, J. and Maes, D. 2013. Effect of a GnRH analogue (Maprelin) on the reproductive performance of gilts and sows. Theriogenology 80:870-877. https://doi.org/ 10.1016/j.theriogenology.2013.07.012

Knox, R. V.; Tudor, K. W.; Rodriguez-Zas, S. L.; Robb, J. A. 2000. Effect of subcutaneous vs intramuscular administration of P.G.600 on estrual and ovulatory responses of prepubertal gilts. Journal of Animal Science 78:1732-1737. https://doi.org/ $10.2527 / 2000.7871732 \mathrm{x}$

Manjarin, R.; Cassar, G.; Sprecher, D. J.; Friendship, R. M.; Dominguez, J. C. and Kirkwood, R. N. 2009. Effect of eCG or eCG Plus hCG on oestrus expression and ovulation in prepubertal gilts. Reproduction in Domestic Animals 44:411-413. https://doi.org/10.1111/j.1439-0531.2008.01089.x

Martinat-Botté, F.; Venturi, E.; Royer, E.; Elleboudt, F.; Furstoss, V.; Ridremont, B. and Driancourt, M. A. 2011. Selection of impubertal gilts by ultrasonography optimizes their oestrus, ovulatory and fertility responses following puberty induction by PG600. Animal Reproduction Science 124:132-137. https://doi.org/10.1016/j. anireprosci.2011.02.018

Muniz, A.; Ravagnani, G. M.; Martins, S. M. M. K.; Andrade, A. F. C. and Moretti, A. S. 2013. Efeitos combinados da restrição alimentar e flushing sobre a fertilidade de marrãs inseminadas artificialmente em diferentes ciclos estrais. Brazilian Journal of Veterinary Research and Animal Science 50:462-467. https://doi.org/10.11606/issn.1678-4456.v50i6p462-467

Patterson, J.; Triemert, E.; Gustafson, B.; Werner, T.; Holden, N.; Pinilla, J. C. and Foxcroft, G. 2016. Validation of the use of exogenous gonadotropins (PG600) to increase the efficiency of gilt development programs without affecting lifetime productivity in the breeding herd. Journal of Animal Science 94:805-815. https://doi.org/10.2527/jas.2015-9705

Stančić, I. B.; Bošnjak, D. V.; Radović, I. B.; Stančić, B. L.; Harvey, R. B. and Anderson, R. C. 2012. Ovarian reaction and estrus manifestation in delayed puberty gilts after treatment with equine chorionic gonadotropin. Reproductive Biology and Endocrinology 10:61. https://doi.org/10.1186/1477-7827-10-61

Tilton, S. L.; Bates, R. O. and Prather, R. S. 1995. Evaluation of response to hormonal therapy prepubertal gilts of different genetic lines. Journal of Animal Science 73:3062-3068. https://doi.org/ $10.2527 / 1995.73103062 \mathrm{x}$

Vangroenweghe, F.; Goossens, L. and Jourquin, J. 2016. An evaluation of gonadotropin-releasing hormone analogue administered to gilts and sows on subsequent reproductive performance and piglet birth weight. Porcine Health Management 2:1. https://doi.org/10.1186/ s40813-016-0018-1

Vianna, W. L.; Pinese, M. E.; Rosseto, A. C.; Oliveira, C. and Moretti, A. S. 2006. Indução da puberdade do cio subsequente em leitoas pré-púberes utilizando gonadotrofinas exógenas. Brazilian Journal of Veterinary Research Animal Science 43:28-32.

Young, L. G.; King, G. J.; Walton, J. S.; McMillan, I. and Klevorick, M. 1990. Reproductive performance over four parities of gilts stimulated to early estrus and mated at first, second or third observed estrus. Canadian Journal of Animal Science 70:483-492. 